\title{
Research on the Evaluation of Customer Satisfaction in B2C E-commerce Enterprises
}

\author{
Cai Huali ${ }^{\mathrm{a}}$, Jiang Yawei ${ }^{\mathrm{b}}$, Song Heliang ${ }^{\mathrm{c}}$ \\ FULL First Author ${ }^{1, a^{*}}$, FULL Second Author ${ }^{2, b}$ and FULL Last Author ${ }^{3, c}$ \\ Quality Management Branch, China National Institute of Standardization, Beijing. China \\ a583451349@qq.com, b352362986@qq.com, c 3833071@qq.com
}

Keywords: B2C, E-commerce, customer satisfaction

Abstract. This paper, by using Chinese customer satisfaction index evaluation model, conducted research on the evaluation of customers' satisfaction towards B2C E-commerce enterprises and presented the customer satisfaction evaluation results for six enterprises with higher market occupation. The evaluation results indicate that Jingdong ranked top (77.6 points), followed by Amazon and Meituan, and Taobao was listed in the last place with 74.2 points. Also, the paper made an analysis of major evaluation indexes.

\section{Introduction}

In rencet years, E-commerce has witnessed a rapid development and played an increasingly impiortant role in people's daily life. However, ensuring complaints have influenced the healthy development of E-ccommerce and even national economy. Thus, it has become a focus of research for the current academia and industry to develop the E-commerce satistory to customers or improve E-commerce customers' satisfaction. Among the researches on customer satisfaction in recent years, there are some typical examples: Dong Xuecheng et al. focused on the research on E-commerce customer satisfaction evalaution model; Zha Jinxiang et al. emphazied the interaction of E-commerce customer satisfaction evaluation indexes; and Zhao Jiayin et al. laid an emphasis on E-commerce customer satisfaction evaluation practice.

This paper, by using the Chinese customer satisfaction index evaluation model, made an survey on the customer satisfaction of B2C E-commerce customers. It proves through practice that the model is both feasible and rational and the evaluation result is comparable among industries and regions.

\section{Evaluation model}

The example of Chinese customer satisfaction evaluation model struture is shown as follows:

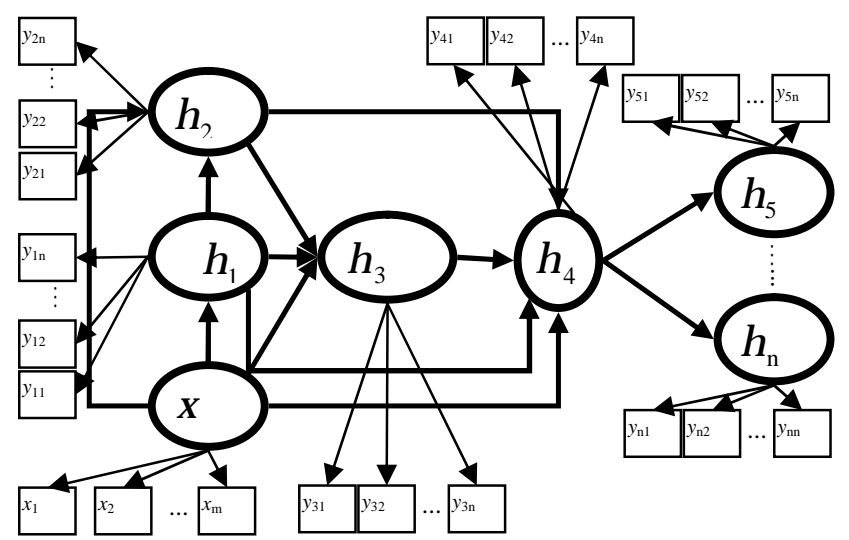

Fig. 1 Example of Customer Satisaction Evaluation Model 
Where, cirles indicate latent variables; the arrows between circles indicate the causal relationship among latent variables; rectangles indicate observable variables; and the arrows between rectangles and circles indicate the observable variable-latent variable response relationship.

The example of mathematical form for structural equation is shown as follows:

$$
\eta=\mathrm{B} \eta+\Gamma \xi+\zeta
$$

Where, $\eta$ means endogenous latent variable; $\xi$ means exogenous latent variable; B means relationship between endogenous latent variables; $\Gamma$ means impact of exogenous latent variable on endogenous latent variable; and $\zeta$ means residual of structural equation, which reflects the parts that are unable to be interpreted in equation and subject to independent normal distribution with average value being zero.

The example of mathematical form measuring the equation is shown as follows:

$$
\begin{aligned}
& \mathrm{X}=\Lambda_{x} \xi+\delta \\
& \mathrm{Y}=\Lambda_{y} \eta+\varepsilon
\end{aligned}
$$

Where, $\mathrm{X}$ means the vector formed by exogenous indexes; $\mathrm{Y}$ means the vector formed by endogenous indexes; $\Lambda_{x}$ means the relationship between exogenous and endogenous indexes, or factor loading matrix of exogenous index on exogenous latent variable; $\Lambda_{y}$ means the relationship between endogenous index and endogenous latent variable or factor loading matrix of endogenous index on endogenous latent variable.

Specifically, as for B2C E-commerce enterprises, the evaluation model is shown in Fig. 2.

Fig. 2

\begin{tabular}{|l|}
\hline Product type \\
\hline Purchasing procedure \\
\hline Product quality \\
\hline Shipping package \\
\hline Delivery speed \\
\hline Online customer service \\
\hline Overall perceived quality \\
\hline Perceived quality \\
\hline Overall expected quality \\
\hline Expected quality \\
\hline Overall image \\
\hline Service characteristics \\
\hline Brand image \\
\hline Overall satisfaction \\
\hline $\begin{array}{l}\text { Satisfaction compared to others } \\
\text { (similar E-commerce enterprises) }\end{array}$ \\
\hline $\begin{array}{l}\text { Satisfaction compared to ideal } \\
\text { services }\end{array}$ \\
\hline $\begin{array}{l}\text { Satisfaction compared to the } \\
\text { expected }\end{array}$ \\
\hline Customer satisfaction \\
\hline Perception towards price under \\
\hline
\end{tabular}




\begin{tabular}{|l|}
\hline given quality \\
\hline Perceived value \\
\hline Customer loyalty \\
\hline Willingness to repurchase \\
\hline Customer recommendation \\
\hline
\end{tabular}

Where, brand image covers customers' evaluation on the overall image of the Company and on the conspicuousness of brand characters; expected quality includes evaluation of customers on the overall expected quality, expected customized quality, expected product reliability and expected service quality; perceived quality includes the evaluation on the overall perceived quality and several quality indexes in relation to quality; perceived value includes the evaluation of customers on the service price of the enterprise under given quality; customer satisfaction includes customers' overall satisfaction on brand service, satisfaction compared with the expected, satisfaction compared to other brands and to ideal services; and customer loyalty includes customers' possible willingness to repurchase brand services and to recommend.

\section{Result}

This survey is made by combination of computer aided phone interview system and online survey and covers B2C enterprises with market occupation ranking top 6 in the 250 major cities of China. Around 250 valid questionnaires were distributed to each enterprise. The respondents were individual consumers aged 18 to 70 who have used the brands surveyed in the previous one year.

The result of calculation is shown in Fig. 3. Jingdong ranks top with highest customer satisfaction with 77.6 points, followed by Amazon and Meituan, and Taobao is listed in the last place with 74.2 points.

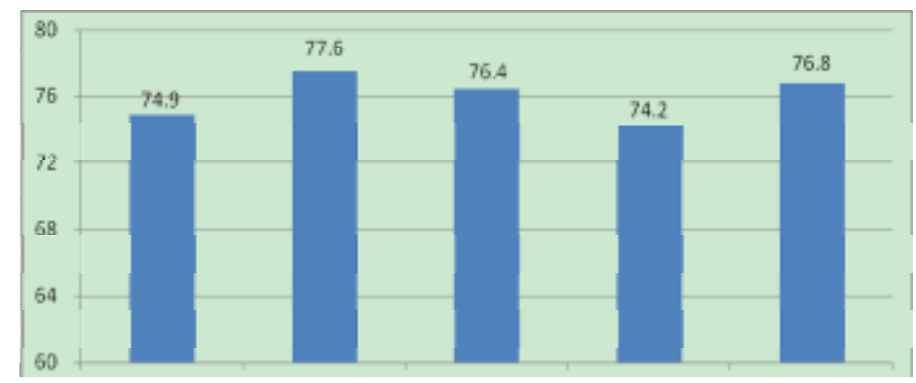

Fig. 3 Evaluation Result of Customers' Satisfaction towards B2C E-commerce Enterprises

\begin{tabular}{|l|}
\hline Dangdang \\
\hline Jingdong \\
\hline Meituan \\
\hline Taobao \\
\hline Amazon \\
\hline
\end{tabular}

Table 1 Customer Satisfaction Evaluation Result in Terms of Major Indexes

\begin{tabular}{|c|c|c|c|c|c|c|c|}
\hline Brand & Service Type & $\begin{array}{l}\text { Purchasing } \\
\text { Convenience }\end{array}$ & Product Quality & Shipping package & $\begin{array}{l}\text { Timeliness of } \\
\text { Delivery }\end{array}$ & Security & $\begin{array}{l}\text { Attitude of } \\
\text { Service Personnel }\end{array}$ \\
\hline Dangdang & 74.07 & 77.73 & 76.57 & 76.9 & 76.76 & 76.71 & 76.67 \\
\hline Jingdong & 75.46 & 78.88 & 76.39 & 78.94 & 77.66 & 77.03 & 77.08 \\
\hline Meituan & 75.93 & 82.28 & 77.53 & 74.95 & 76.03 & 77.53 & 77.15 \\
\hline Taobao & 83.49 & 84.71 & 61.49 & 71.26 & 67.07 & 73.73 & 72.8 \\
\hline Amazon & 74.03 & 79.71 & 78.8 & 80.37 & 78.2 & 78.26 & 76.51 \\
\hline
\end{tabular}


Among the customer satisfaction evaluation result in terms of major indexes, Taobao ranks top in service type (83.49) and in purchasing convenience (84.71); Amazon ranks top in product quality (78.8), in shipping package (78.2) and in security (78.26); and Metuan ranks top in the attitudes of service personnel (77.15).

\section{Summary}

This paper, by using Chinese customer satisfaction index evaluation model, conducted research on the evaluation of customer satisfaction in B2C E-commerce enterprises, presented the customer satisfaction evaluation results for six enterprises with higher market occupation and made an analysis of major indexes.

\section{Acknowledgement}

This work was funded by the Dean fund project of China National Institute of Standardization under grant No. 642015Y-4009, the National Key Technology R\&D Program of the Ministry of Science and Technology under grant No. 2013BAK04B02 and 2013BAK04B04.

\section{References}

[1] Dong Xuecheng, Research on the Application of DEA in E-commerce Customer Satisfaction Evaluation: with B2C E-commerce Enterprises as Example. Capital University of Economics and Business, Beijing China, March 2013.

[2] Zhao Jiayin, Evaluation on Customer Satisfaction of Dangdang Online Bookstore. Nanjing University of Science and Technology, December 2012

[3] Zha Jinxiang, Research on the Relationship between B2C E-commerce Customers' Value and Loyalty. Zhejiang University, May 2006. 